\title{
Molecular Epidemiological Characteristics of Human Rhinovirus Circulating in Shanghai, 2012 - 2020
}

\section{Haixia Jiang (D 19211300004@fudan.edu.cn )}

Fudan University Affiliated Public Health Clinical Center: Shanghai Public Health Clinical Center https://orcid.org/0000-0002-6731-6419

\section{Chunyi Yang}

Fudan University Affiliated Public Health Clinical Center: Shanghai Public Health Clinical Center

Yanping Lu

Fudan University Affiliated Public Health Clinical Center: Shanghai Public Health Clinical Center Zhigang Yi

Fudan University Affiliated Public Health Clinical Center: Shanghai Public Health Clinical Center

Wei Wang

Shanghai Public Health Clinical Center

\section{Research Article}

Keywords: human rhinovirus, genotyping, epidemiology

Posted Date: August 17th, 2021

DOI: https://doi.org/10.21203/rs.3.rs-802176/v1

License: @ (i) This work is licensed under a Creative Commons Attribution 4.0 International License. Read Full License 


\section{Abstract \\ Background}

Human Rhinoviruses (HRVs) are a common respiratory virus causing acute exacerbations of asthma, chronic obstructive pulmonary disease (COPD) and other related diseases. The sequence of 5 ' untranslated region (UTR) and VP4/VP2 coding region of the genome are usually analyzed to classify HRV as HRV-A, HRV-B and HRV-C. Given the interest for new viral strains, we identified the phylogenetic characteristics and molecular epidemiological analysis of human rhinovirus in Shanghai from 2012 to 2020.

\section{Methods}

6711 throat swabs and sputum samples from patients with acute respiratory infection (ARI) were collected, then the real-time reverse-transcriptase polymerase chain reaction (RT-PCR) method was used to detect HRV. And the fragment of 5 ' untranslated region (5'UTR) and the VP4/VP2 region were amplified for sequencing and gene typing.

\section{Results}

In total, 480/6711(7.2\%) HRV-positive samples were detected from 2012-2020, in which 160 samples were further genotyped to HRV-A (109/160, 68.13\%), HRV-B (32/160, 20.00\%), HRV-C (19/160, 11.88\%). We found 13 samples with unclassified results using $5^{\prime}$ UTR. Then, these unclassified sample were genotyped to HRV-A and HRV-C by sequencing the VP4/VP2 region. The high incidence of HRV infection occurs in the fall and it is more prevalent in children than in adults.

\section{Conclusion}

Our study suggests that it is very significant to continuously detect and analyze the genotype distribution and epidemic trend of HRV, which can provide data support for disease prevention and treatment. And the $5^{\prime}$ UTR and VP4/VP2 should be combined for HRV genotyping accurately.

\section{Introduction}

Human Rhinoviruses (HRVs) are positive-sense, single-stranded ribonucleic acid (RNA) viruses belonging to the Enterovirus genus in the Picornaviridae family[1]. HRVs are one of the most common respiratory pathogen associated with both upper and lower respiratory tract illness[2].

The HRV genome is approximately $7.2 \mathrm{~kb}$ in length, a single open reading frame capped by a 5 'untranslated region( $5^{\prime} \mathrm{UTR}$ ) and a short viral primer protein (VPg). The viral genome consists of a single gene encoding 11 proteins: four capsid proteins and seven non-structural proteins. Four structural proteins: VP1, VP2, VP3 and VP4 together participate in the assembly of viral capsids[3]. Rhinovirus was first isolated from the specimens of patients with respiratory tract infection by Pelon et al in 1956 by means of tissue culture[4]. HRVs have 
extensive genetic diversity of RNA viruses and classified phylogenetically into 3 species (HRV-A, HRV-B, HRVC) [5]. Types A and B were discovered in the early 1990s, while HRV-C was detected until 2006 due to cannot be cultured in histocyte [6]. With the development of molecular biology technologies, multiple new rhinovirus subtypes have been found $[7,8]$. Currently, more than 150 rhinoviruses serotypes have been identified and without a uniform antigenic epitope, which make the discovery of HRV vaccines difficult [9].

In recent years, increasing number of studies have shown that in addition to causing acute respiratory tract diseases, HRV infection could also lead to the aggravation of asthma in children and chronic obstructive pulmonary disease (COPD) in middle-aged and elderly people[9]. Epidemiological investigation of the virus is a powerful tool to control the spread of disease.

In this study, we identified the genotypes of HRV from clinical samples collected in Shanghai from sentinel hospitals, during 2012 to 2020 . HRV-positive samples were typed by analyzing the nucleotide sequence of 5'UTR and VP4/VP2 region.

\section{Materials And Methods}

Clinical samples collection

From January 2012 to April 2020, 6711 throat swabs or sputum samples of patients were collected from 6 sentinel hospitals in Shanghai (Shanghai Public Health Clinical Center, Shanghai Xinhua Hospital, Shanghai Tongren Hospital, Shanghai East Hospital, Shanghai No.5 People's Hospital and Shanghai Pediatric Hospital). Clinical information related to patients was recorded. All of the specimens were kept in virus transport medium and sent to the laboratory immediately. The study was approved by the ethic committee of Shanghai Public Health Clinical Center (2018-S045-02)

Laboratory detection and subtype classification of rhinovirus

Viral RNA was extracted from specimen by using Nucleic acid extraction and purification kit (BioGerm, Shanghai). The extracted nucleic acids can be directly detected using One Step PrimeScript RT-PCR Kit (TaKaRa ${ }^{\circledR}$, Japan) for the Real-Time polymerase chain reaction (RT-PCR). RT-PCR was performed at $42^{\circ} \mathrm{C}$ for $10 \mathrm{~min}, 95^{\circ} \mathrm{C}$ for $1 \mathrm{~min}$ followed by 40 cycles at $95^{\circ} \mathrm{C}$ for $10 \mathrm{~s}$, and at $55^{\circ} \mathrm{C}$ for $1 \mathrm{~min}$.

HRV positive samples were screened out and transcribed to cDNA by using the SuperScript ${ }^{\circledR}$ III first-strand synthesis system (Invitrogen, USA). Human rhinovirus cDNA samples were then amplified using 5'UTR or VP4/VP2 primers. The lengths of 5'UTR and VP4/VP2 amplicons were $390 \mathrm{bp}$ and 610bp respectively forming by Platinum ${ }^{\text {TM }}$ SuperFi' ${ }^{\text {TM }}$ DNA Polymerase kits (Invitrogen, USA). PCR was performed at $98^{\circ} \mathrm{C}$ for $30 \mathrm{~s}$ followed by 45 cycles at $98^{\circ} \mathrm{C}$ for $10 \mathrm{~s}$, at $55^{\circ} \mathrm{C}$ for $10 \mathrm{~s}$, at $72^{\circ} \mathrm{C}$ for $30 \mathrm{~s}$, and at $72^{\circ} \mathrm{C}$ for 10 min for a final extension. Primers targeting the amplification sequences and RT-PCR of HRV were listed in Table 1. DNA products were extracted from agarose gels by using QIAquick Gel Extraction Kit (Qiagen), and were linked with pZero-Blunt vector. The plasmid pZero-Blunt was provided by Key Laboratory of Medical Molecular Virology, Shanghai Medical College, Fudan University, Shanghai, China. 
Table 1

HRV specific primes used for RNA amplification and detection.

\begin{tabular}{|lll|}
\hline PCR & Name & Sequence \\
\hline RT-PCR & HRV-F & 5'-CTCCGGCCCCTGAATRYGGCTAA-3' \\
\cline { 2 - 3 } & HRV-R & 5'-TCIGGIARYTTCCASYACCAICC-3' $^{\prime}$ \\
\hline Sequencing 5'UTR & HRV-5'UTR -F & 5'-CAAGCACTTCTGTTWCCCC-3' $^{\prime}$ \\
\cline { 2 - 3 } & HRV-5'UTR -R & 5'-ACGGACACCCAAAGTAGT-3' \\
\hline Sequencing VP4/VP2 & HRV- VP4/VP2 -F & 5'-GCCCCTGAATGYGGCTAA-3' \\
\hline & HRV- VP4/VP2 -R & 5'-GGTAAYTTCCACCACCANCC-3' \\
\hline
\end{tabular}

Sequence and statistical analysis

The genomic sequences were assembled using SnapGene software. The alignments were compared, and the phylogenetic tree was generated using MEGA software (version X). Identities between the strains were calculated using BioEdit. Statistical analysis and data management were implemented using the IBM SPSS Statistics software (version 20.0, IBM Corporation, Armonk, NY, USA) and GraphPad Prism (version 8.01, GraphPad Software, La Jolla, CA, USA). Quantitative data were tested by chi-square test and the p-value of < 0.05 was considered statistically significant.

\section{Result}

Respiratory virus detection

From January 2012 to April 2020, 6711 respiratory specimens were detected by RT-PCR for HRV. A total of 480 samples were HRV positive samples, and 160 samples were screened out after removing repetitive ones from the same patients. Of the 160 patients included in this study, 89(55.6\%) were male and 71(44.4\%) were female. We compared whether there were differences in genotypes between the sexes $(X 2=3.070, P=0.215>$ 0.05).(Table 2) 
Table 2

Positive results of HRV detection in Shanghai from 2012 to 2020, the GBD 2000.

\begin{tabular}{|c|c|c|c|c|c|c|c|}
\hline Items & $\begin{array}{l}\text { HRV positive } \\
\text { samples }\end{array}$ & $\begin{array}{l}\text { Frequency } \\
\text { (\%) }\end{array}$ & ${ }_{A}^{H R V-}$ & $\begin{array}{l}\mathrm{HRV}- \\
\mathrm{B}\end{array}$ & $\begin{array}{l}\mathrm{HRV}- \\
\mathrm{C}\end{array}$ & $x^{2}$ & $\mathbf{P}$ \\
\hline \multicolumn{8}{|l|}{ Gender } \\
\hline Male & 89 & 55.63 & 56 & 22 & 11 & 3.070 & 0.215 \\
\hline \multirow[t]{2}{*}{ Female } & 71 & & 53 & 10 & 8 & & \\
\hline & & 44.38 & & & & & \\
\hline \multicolumn{8}{|l|}{ Season } \\
\hline Spring & 20 & 12.50 & 16 & 4 & 0 & 17.908 & 0.004 \\
\hline Summer & 38 & 23.75 & 34 & 3 & 1 & & \\
\hline Fall & 58 & 36.25 & 36 & 12 & 10 & & \\
\hline Winter & 44 & 27.50 & 23 & 13 & 8 & & \\
\hline \multicolumn{8}{|c|}{$\begin{array}{l}\text { Age } \\
\text { group(year) }\end{array}$} \\
\hline $0 \sim 2$ & 3 & 1.88 & 1 & 1 & 1 & 23.880 & 0.017 \\
\hline $3-14$ & 58 & 36.25 & 41 & 7 & 10 & & \\
\hline $15-29$ & 25 & 15.63 & 21 & 2 & 2 & & \\
\hline $30-44$ & 26 & 16.25 & 16 & 8 & 2 & & \\
\hline $45-59$ & 17 & 10.63 & 11 & 6 & 0 & & \\
\hline $60-69$ & 15 & 9.38 & 8 & 6 & 1 & & \\
\hline $70-79$ & 12 & 7.50 & 10 & 1 & 1 & & \\
\hline$\geq 80$ & 4 & 2.50 & 1 & 1 & 2 & & \\
\hline
\end{tabular}

Seasonal dynamics of HRV

The detection frequency of HRV in different seasons were $12.5 \%$ (20/160) in spring, $23.7 \%(38 / 160)$ in summer, $36.3 \%$ (58/160) in autumn, and $27.5 \%(44 / 160)$ in winter. The peak incidence of HRV infection occurred mainly in autumn, with statistical differences in HRV genotype detection rates between seasons. ( $\chi 2$ $=17.908, \mathrm{P}=0.004<0.05$ ). (Table 2) We also compared the HRV detections in different months from 20122020, which showed total HRV in 2012 and 2020 is higher compared to other years and the highest detection frequency in October. (Fig. 1,2)

Distribution of age groups

The minimum age of the collected HRV-positive specimens was 2 years and the maximum age was 87 years, and they were divided into 8 groups of $0-2,3-14,15-29,30-44,45-59,60-69,70-79$, and $\geq 80$ years. The 
detection rates were $1.88 \%, 36.25 \%, 15.63 \%, 16.25 \%, 10.63 \%, 9.38 \%, 7.50 \%$, and $2.50 \%$, respectively, with the highest HRV detection rate in the 3-14 years age group, which may be attributed to the larger number of specimens collected from children. (Fig. 3) (Table 2$)(X 2=23.880, P=0.017<0.05)$

Co-infection of HRV

There were 52 cases of mixed other respiratory viral infections in all HRV-positive samples, among which the highest number of cases of HRV co-infection with influenza was 12 , accounting for $23.1 \%$, followed by bocavirus or adenovirus, accounting for $17.3 \%$. (Table 3 )

Table 3

Co-infections of HRV with other respiratory viruses.

\begin{tabular}{|lll|}
\hline Co-infections & Infection cases & Frequency(\%) \\
\hline HRV & 160 & 100 \\
\hline Flu + HRV & 12 & 7.50 \\
\hline RSV + HRV & 5 & 3.13 \\
\hline BOV + HRV & 9 & 5.63 \\
\hline PIV + HRV & 5 & 3.13 \\
\hline RSV + HRV & 7 & 4.37 \\
\hline ADV + HRV & 9 & 5.62 \\
\hline RSV + ADV + HRV & 4 & 2.50 \\
\hline HMPV + BOV + HRV & 1 & 0.63 \\
\hline
\end{tabular}

Phylogenetic analysis of 5'UTR

The sequencing results were compared and analyzed with the reference sequences selected from Genbank. Multiple sequence alignment and phylogenic tree were generated by MEGA-X program and ClustalW (Fig. 4). The evolutionary tree showed that the detected HRV-positive samples were divided into 3 genetic clusters A, B and C, accounting for $61.25 \%(98 / 160), 20.00 \%(32 / 160)$ and $10.62 \%(17 / 160)$, respectively. The HRV-A, B, C clusters had identities of $66.2 \% \sim 100 \%, 76.7 \% \sim 100 \%$ and $65.0 \% \sim 100 \%$ for nucleotide sequences within individual groups, which indicate that HRV-A, $C$ was highly variable than B. On the contrary, the variation of HRV-B sequence was relatively stable. In the phylogenetic tree of 5'UTR, 6 of the HRV-A genotypes and 5 of the HRV-C genotypes were present in the same branch. We analyzed the identities of these 11 samples (78.9\%-100\%), which was higher than the corresponding genotypes (Fig. 5) (Table 3).

Unclassified samples

In the genotyping using 5'UTR sequences, there were 13 samples unclassified, and we performed VP4/VP2 genome sequencing of these samples, which 10 samples were all HRV-A type, others were HRV-C. (Fig. 6) One particular strain was distributed under HRV-A clade in the 5' UTR phylogenetic tree and under HRV-C clade in 
the VP4/VP2 phylogenetic tree. This samples that grouped as C in VP4/VP2 but as A in 5'UTR are denoted as $\mathrm{C} / \mathrm{A}[10]$.

\section{Discussion}

Human rhinovirus (HRV) is one of the most important respiratory viruses causing influenza-like illnesses, and HRV also causes pediatric asthma, chronic obstructive pulmonary disease (COPD), acute otitis media, sinusitis, pneumonia, and bronchopneumonia[9, 11, 12], posing a serious risk to human health. Studies have shown that HRV types A and C cause more severe clinical symptoms compared to HRV type B and are strongly associated with exacerbation of asthma disease in children[13]. As a result, drug and vaccine development for HRV may should focus mainly on the two subtypes A, C. Huang $T$ and coworkers roundly analyzing HRV genotypes, they found that more than half of HRV-C types contain a variable length gene fragment identical to the $5^{\prime}$ end of HRV-A, and HRV-C was divided into two new subspecies: HRV-Cc and HRV$\mathrm{Ca}$. It suggests that viral recombination may be the result of co-infection with $A$ and $C[14]$, and that HRV-C and $\mathrm{C} / \mathrm{A}$ subtypes are more likely to be detected in the asthmatic patients of preschool age [10], and the recombination between $\mathrm{A}$ and $\mathrm{C}$ subtypes provides an opportunity for continuous mutation in HRV, but creates challenges for disease treatment and research.

In this study, the nucleotide sequence of 5'UTR region was efficiently amplified by PCR and ligated into the related vector, which is high specific and sensitive and can eliminate the interference of other pathogens in the sequencing process. Although, there were 13 samples detected as unclassified, we also further analyzed their sequences using the VP4/VP2 regions. The detection rate of rhinovirus among respiratory viruses was $7.2 \%$, and among the 160 HRV-positive samples, the proportions of genotypes A, B, and C were $68.13 \%, 20.00 \%$, and $11.88 \%$, respectively, which indicated that HRV-A was the main prevalence of rhinovirus in Shanghai during 2012-2020. This is broadly in line with the results of related studies[15-17].

The detection rate of HRV is related to seasonal, age, gender and regional differences.

In the previous study, HRV outbreak pattern was identified that occurred during the spring and fall seasons [5]. It was noticed that the presence of HRV was detected in all season, with the highest prevalence in fall (36.25\%;58/160), which was consistent with previous studies.

Among the several age groups, the highest HRV detection rate of $36.25 \%$ was found in the 3-14 years group, which may be due to the higher number of children samples collected. The morbidity of HRV is high in schoolaged children and respiratory viral infections are an important cause of mortality in children under 5 years of age [18], which may be associated with an underdeveloped adaptive immune response system in infants and young children. Positive-sense RNA genomes contain a short viral priming protein(VPg), which plays essential functions in evading host recognition[19]. The mechanisms involved in viral VPg remain to be investigated.

Among the 160 positive samples, influenza was the most common co-infecting respiratory virus. High incidence of both influenza and parainfluenza has been reported during the onset of HRV[20]. Co-infection with other viruses or bacteria may increase disease severity[21]. HRV promotes bacterial endocytosis, thereby increasing the susceptibility of pathogens to invade host cells[22]. Therefore, in the prevention and control of respiratory virus infection, we should strengthen the monitoring of other pathogens. 
The results of phylogenetic analysis showed that during 2012-2020, three genotypes of HRV-A, B, C were coprevalent, with A predominant and B, C following. In our phylogenetic tree, two HRV-A types $(4204,5980)$ appeared among the HRV-C group. This phenomenon can occur when some HRV-Cs have 5'UTRs with similar phylogenetic origins in HRV-A[23]. The existence of multiple branches under the same genotype in the phylogenetic tree indicates that there is high variation within the same genotype. Recombination between different subtypes may offer an opportunity for virus evolution[24]. RNA viruses mutate through recombinant variation to improve their fitness and evade the host immune system[25-27]. Type $A$ and $C$ recombination is mostly found in the 5'UTR and 2A protease gene regions[28], and it is uncertain whether recombination in this region is useful for virus entry into host cells and relevant for HRV vaccine and drug development.

Genotyping of HRV-based sequence similarity directly from clinical specimens replaces cell culture for viral isolation, thus greatly reducing the time to detect the three HRV types. In molecular genetics, due to the highly conserved nucleotide sequences in the 5' UTR, VP4/VP2 regions, these sequences are usually used to classify HRV genotypes[29]. The 5' UTR detection has been used to successfully classify HRV and provides a higher sensitivity compared to VP4/ VP2 region, which is susceptible to a lower binding efficiency[30, 31]. VP4/VP2 sequences can be better used for type $A$ and $C$ identification in epidemiological studies[29]. 5' UTR assay can be used as a powerful tool to address the sensitivity problem regarding capsid region-based genotyping[32]. Although, the 5' UTR did not successfully segregate the unclassified strains into HRV-A and HRV-C, this does not exclude its importance and utility in typing of novel strains of HRV. As a consequence, there are some issues to consider when using the $5^{\prime}$ UTR for genetic typing unclassified strains cannot be well segregated, and there will require the joint use of $5^{\prime}$ UTR and VP4/VP2 regions for resolution.

This study analyzed the epidemiological variation of rhinovirus in respiratory samples from 2012 to 2020 in Shanghai, which utilize molecular diagnostic assays to provide basic data for the prevention, control and treatment of respiratory diseases.

\section{Declarations}

\section{Acknowledgments}

We would like to thank Miss. Lingling Pang at Shanghai Public Health Clinical Center, Fudan University, Shanghai 201508, China for her assistance with the experiments and valuable discussion.

\section{Author Contributions}

WW and ZY conceived and designed the study. WW and ZY provided precious suggestions on the results. HJ performed the experiments, analyzed the data and wrote the manuscript. $\mathrm{CY}$ and $\mathrm{YL}$ collected and screened the samples. All authors read the manuscript and approved the submitted version.

\section{Funding}


This work was supported by grants from the National Science and Technology Major Project of China(2017ZX10103009-001) and National Natural Science Foundation of China (81301422)

Conflict of interest None of the authors have any competing interests to declare.

\section{References}

1. Vos LM, Bruyndonckx R, Zuithoff NPA, Little P, Oosterheert JJ, Broekhuizen BDL, Lammens C, Loens K, Viveen M, Butler CC, et al: Lower respiratory tract infection in the community: associations between viral aetiology and illness course. Clin Microbiol Infect 2020.

2. Bizot E, Bousquet A, Charpie M, Coquelin F, Lefevre S, Le Lorier J, Patin M, See P, Sarfati E, Walle S, et al: Rhinovirus: A Narrative Review on Its Genetic Characteristics, Pediatric Clinical Presentations, and Pathogenesis. Front Pediatr 2021, 9:643219.

3. Jacobs SE, Lamson DM, St George K, Walsh TJ: Human rhinoviruses. Clin Microbiol Rev 2013, 26:135162.

4. <Rhinoviruses Methods and Protocols .pdf >.

5. Lee WM, Lemanske RF, Jr., Evans MD, Vang F, Pappas T, Gangnon R, Jackson DJ, Gern JE: Human rhinovirus species and season of infection determine illness severity. Am J Respir Crit Care Med 2012, 186:886-891.

6. $\quad$ Nakauchi M, Nagata N, Takayama I, Saito S, Kubo H, Kaida A, Oba K, Odagiri T, Kageyama T: Propagation of Rhinovirus $\mathrm{C}$ in Differentiated Immortalized Human Airway HBEC3-KT Epithelial Cells. Viruses 2019, 11.

7. Adams MJ, Lefkowitz Ej Fau - King AMQ, King Am Fau - Bamford DH, Bamford Dh Fau - Breitbart M, Breitbart M Fau - Davison AJ, Davison Aj Fau - Ghabrial SA, Ghabrial Sa Fau - Gorbalenya AE, Gorbalenya Ae Fau - Knowles NJ, Knowles Nj Fau - Krell P, Krell P Fau - Lavigne R, et al: Ratification vote on taxonomic proposals to the International Committee on Taxonomy of Viruses (2015).

8. Mahony JB, Petrich A Fau - Smieja M, Smieja M: Molecular diagnosis of respiratory virus infections.

9. Greenberg SB: Update on Human Rhinovirus and Coronavirus Infections. Semin Respir Crit Care Med 2016, 37:555-571.

10. Ratnamohan VM, Zeng F, Donovan L, Maclntyre CR, Kok J, Dwyer DE: Phylogenetic analysis of human rhinoviruses collected over four successive years in Sydney, Australia. Influenza Other Respir Viruses 2016, 10:493-503.

11. Custovic A, Belgrave D, Lin L, Bakhsoliani E, Telcian AG, Solari R, Murray CS, Walton RP, Curtin J, Edwards MR, et al: Cytokine Responses to Rhinovirus and Development of Asthma, Allergic Sensitization, and Respiratory Infections during Childhood. Am J Respir Crit Care Med 2018, 197:1265-1274. 
12. Allard B, Levardon H, Esteves P, Celle A, Maurat E, Thumerel M, Girodet PO, Trian T, Berger P: Asthmatic Bronchial Smooth Muscle Increases CCL5-Dependent Monocyte Migration in Response to Rhinovirus-Infected Epithelium. Front Immunol 2020, 10.

13. Jartti T, Bonnelykke K, Elenius V, Feleszko W: Role of viruses in asthma. Semin Immunopatho/ 2020, 42:61-74.

14. Huang T, Wang W, Bessaud M, Ren P, Sheng J, Yan H, Zhang J, Lin X, Wang Y, Delpeyroux F, Deubel V: Evidence of recombination and genetic diversity in human hinoviruses in children with acute respiratory infection. PLoS One 2009, 4:e6355.

15. Lu QB, Wo Y, Wang LY, Wang HY, Huang DD, Zhang XA, Liu W, Cao WC: Molecular epidemiology of human rhinovirus in children with acute respiratory diseases in Chongqing, China. Sci Rep 2014, 4:6686.

16. van der Linden L, Bruning AH, Thomas XV, Minnaar RP, Rebers SP, Schinkel J, de Jong MD, Pajkrt D, Wolthers KC: A molecular epidemiological perspective of rhinovirus types circulating in Amsterdam from 2007 to 2012. Clin Microbiol Infect 2016, 22:1002 e1009-1002 e1014.

17. Zlateva KT, van Rijn AL, Simmonds P, Coenjaerts FEJ, van Loon AM, Verheij TJM, de Vries JJC, Little P, Butler CC, van Zwet EW, et al: Molecular epidemiology and clinical impact of rhinovirus infections in adults during three epidemic seasons in 11 European countries (2007-2010). Thorax 2020, 75:882-890.

18. Walker CLF, Rudan I, Liu L, Nair H, Theodoratou E, Bhutta ZA, O'Brien KL, Campbell H, Black RE: Global burden of childhood pneumonia and diarrhoea.

19. Goodfellow I: The genome-linked protein VPg of vertebrate viruses - a multifaceted protein. Curr Opin Virol 2011, 1:355-362.

20. Nowak MA-O, Sordillo EA-O, Gitman MA-O, Paniz Mondolfi AA-O: Coinfection in SARS-CoV-2 infected patients: Where are influenza virus and rhinovirus/enterovirus?

21. Goka EA, Vallely PJ, Mutton KJ, Klapper PE: Single, dual and multiple respiratory virus infections and risk of hospitalization and mortality. Epidemiol Infect 2015, 143:37-47.

22. Jubrail J, Africano-Gomez K, Herit F, Mularski A, Bourdoncle P, Oberg L, Israelsson E, Burgel P-R, Mayer G, Cunoosamy DM, et al: Arpin is critical for phagocytosis in macrophages and is targeted by human rhinovirus. Embo Rep 2020, 21:e47963.

23. Faux CE, Arden KE, Lambert SB, Nissen MD, Nolan TM, Chang AB, Sloots TP, Mackay IM: Usefulness of published PCR primers in detecting human rhinovirus infection. Emerg Infect Dis 2011, 17:296-298.

24. Schibler M, Piuz I, Hao W, Tapparel C: Chimeric rhinoviruses obtained via genetic engineering or artificially induced recombination are viable only if the polyprotein coding sequence derives from the same species. J Virol 2015, 89:4470-4480. 
25. Weisblum Y, Schmidt F, Zhang F, DaSilva J, Poston D, Lorenzi JC, Muecksch F, Rutkowska M, Hoffmann $\mathrm{HH}$, Michailidis E, et al: Escape from neutralizing antibodies by SARS-CoV-2 spike protein variants. eL ife 2020, 9.

26. Ramirez BC, Simon-Loriere E, Galetto R, Negroni M: Implications of recombination for HIV diversity. Virus Res 2008, 134:64-73.

27. Nagaraja P, Alexander HK, Bonhoeffer S, Dixit NM: Influence of recombination on acquisition and reversion of immune escape and compensatory mutations in HIV-1. Epidemics 2016, 14:11-25.

28. Palmenberg AC, Gern JE: Classification and evolution of human rhinoviruses. Methods in molecular biology (Clifton, NJ) 2015, 1221.

29. Mclntyre CL, Knowles NJ, Simmonds P: Proposals for the classification of human rhinovirus species A, B and C into genotypically assigned types. J Gen Virol 2013, 94:1791-1806.

30. Kiang D, Kalra I, Yagi S, Louie JK, Boushey H, Boothby J, Schnurr DP: Assay for 5 ' noncoding region analysis of all human rhinovirus prototype strains. J Clin Microbiol 2008, 46:3736-3745.

31. Denlinger LC, Sorkness RI Fau - Lee W-M, Lee Wm Fau - Evans MD, Evans Md Fau - Wolff MJ, Wolff Mj Fau - Mathur SK, Mathur Sk Fau - Crisafi GM, Crisafi Gm Fau - Gaworski KL, Gaworski KI Fau - Pappas TE, Pappas Te Fau - Vrtis RF, Vrtis Rf Fau - Kelly EA, et al: Lower airway rhinovirus burden and the seasonal risk of asthma exacerbation.

32. Savolainen-Kopra C, Blomqvist S, Smura T, Roivainen M, Hovi T, Kiang D, Kalra I, Yagi S, Louie JK, Boushey $\mathrm{H}$, et al: $\mathbf{5}$ ' noncoding region alone does not unequivocally determine genetic type of human rhinovirus strains. J Clin Microbio/ 2009, 47:1278-1280.

\section{Tables}

Table 4 Sequence Identity Matrix.

The sequence identity matrix of 11 sequence that were present in the same branch were analyzed by Bioedit. 


\begin{tabular}{|lllllllllll|l|}
\hline ID & $\mathbf{4 2 1 7}$ & $\mathbf{4 2 3 4}$ & $\mathbf{2 9 9}$ & $\mathbf{1 7 1}$ & $\mathbf{1 0 3 8 4}$ & $\mathbf{2 6 0}$ & $\mathbf{2 2 7}$ & $\mathbf{2 1 2}$ & $\mathbf{9 5 5 4}$ & $\mathbf{3 9 8 3}$ & $\mathbf{5 7 4 4}$ \\
\hline $\mathbf{4 2 1 7}$ & 1 & & & & & & & & & & \\
\hline $\mathbf{4 2 3 4}$ & 1 & 1 & & & & & & & & \\
\hline $\mathbf{2 9 9}$ & 0.900 & 0.900 & 1 & & & & & & & \\
\hline $\mathbf{1 7 1}$ & 0.903 & 0.903 & 0.992 & 1 & & & & & & \\
\hline $\mathbf{1 0 3 8 4}$ & 0.861 & 0.861 & 0.862 & 0.854 & 1 & & & & & \\
\hline $\mathbf{2 6 0}$ & 0.842 & 0.842 & 0.828 & 0.830 & 0.789 & 1 & & & & \\
\hline $\mathbf{2 2 7}$ & 0.842 & 0.842 & 0.828 & 0.830 & 0.789 & 1 & 1 & & & \\
\hline $\mathbf{2 1 2}$ & 0.842 & 0.842 & 0.828 & 0.830 & 0.789 & 0.997 & 0.997 & 1 & & \\
\hline $\mathbf{9 5 5 4}$ & 0.836 & 0.836 & 0.824 & 0.827 & 0.821 & 0.827 & 0.827 & 0.827 & 1 & & \\
\hline $\mathbf{3 9 8 3}$ & 0.834 & 0.834 & 0.822 & 0.824 & 0.819 & 0.825 & 0.825 & 0.825 & 0.997 & 1 & \\
\hline $\mathbf{5 7 4 4}$ & 0.841 & 0.841 & 0.829 & 0.832 & 0.821 & 0.827 & 0.827 & 0.827 & 0.992 & 0.989 & 1 \\
\hline
\end{tabular}

\section{Figures}

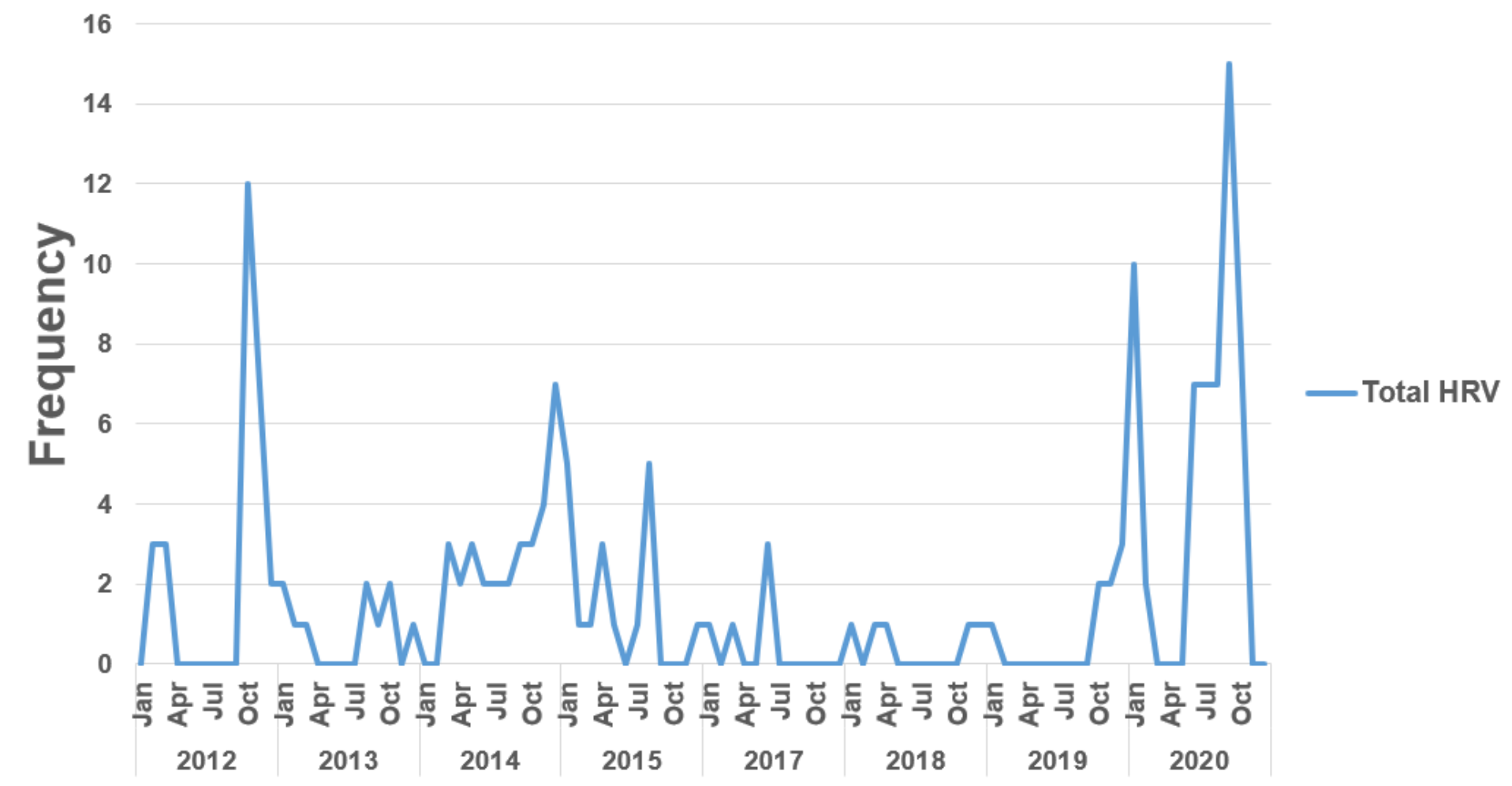

Figure 1

Monthly distribution of HRV positive frequency in 160 respiratory samples. The amount of total HRV observed in each month, pooling the years 2012-2020. The year 2009 was excluded, as RV circulation in that year was atypical. 


\section{Frequency of HRV-A, HRV-B and HRV-C infections per month}

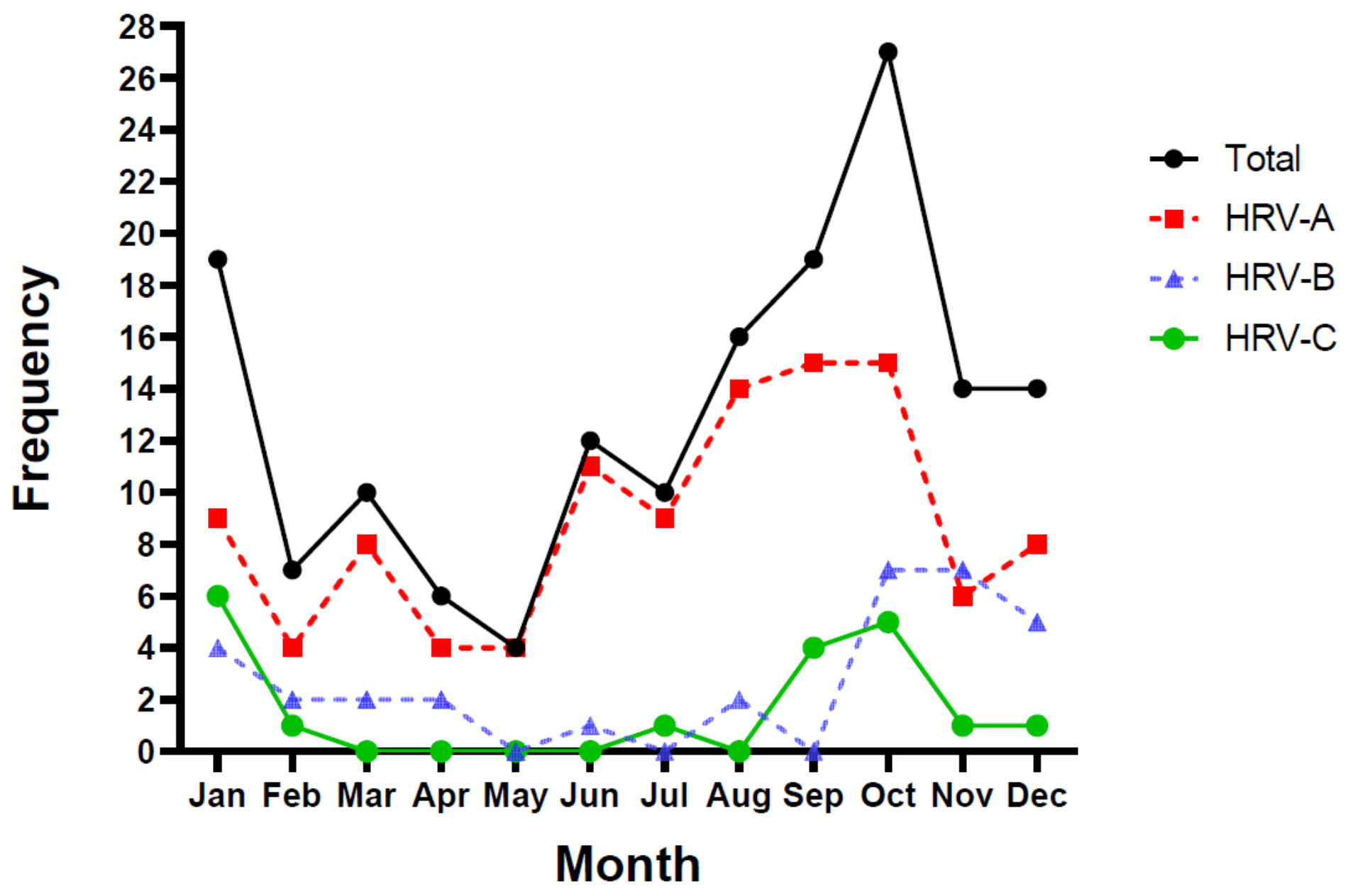

Figure 2

The frequency of viral infections detected monthly is shown for HRV species. The frequency of viral infections detected monthly with total HRV, HRV-A, B and C was analyzed from 2012 to 2020. 


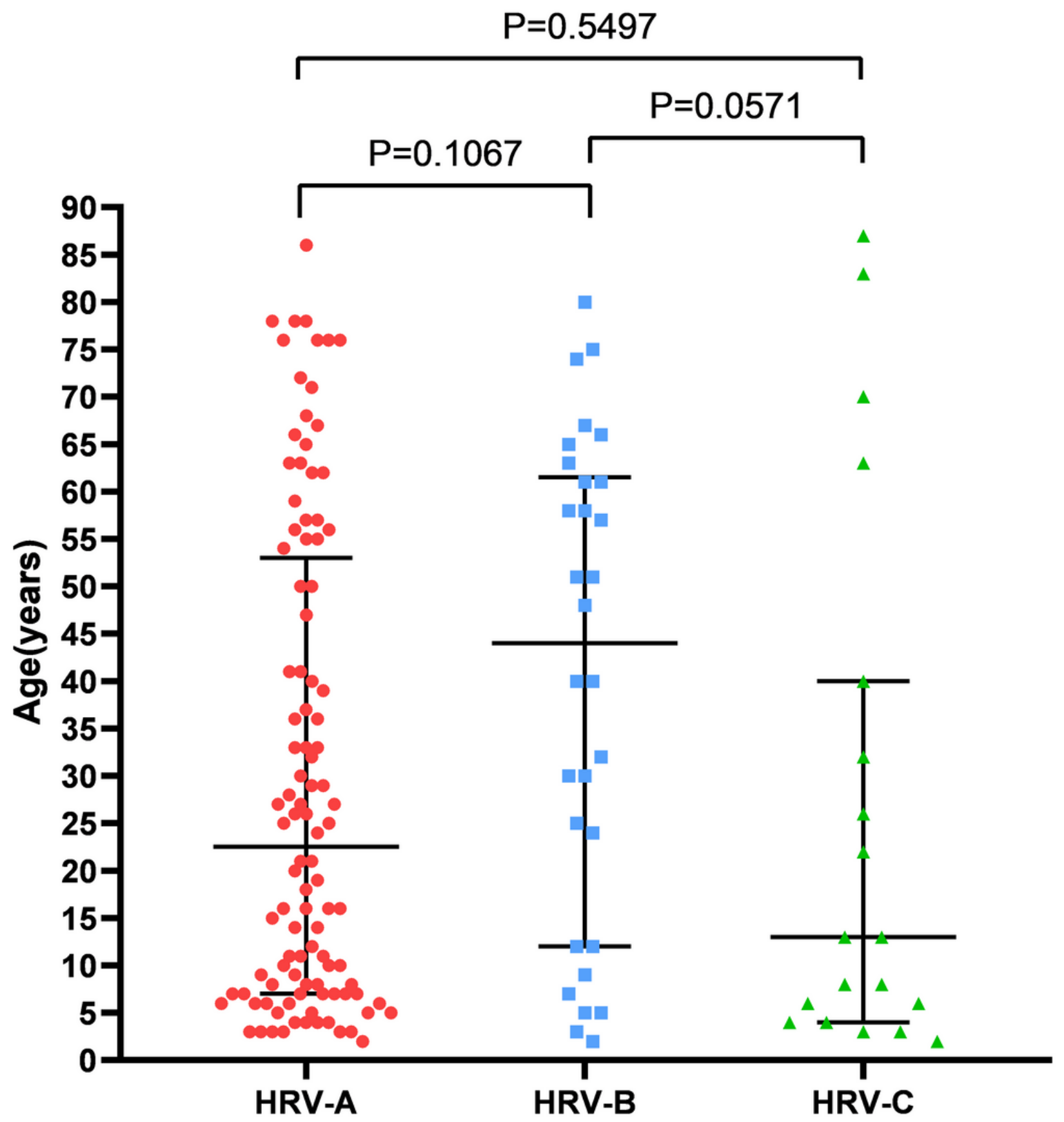

Figure 3

Age distribution of different types of Human rhinovirus A, B or C. Different icons to represent type A(HRV-A), $\mathrm{HRV}-\mathrm{B}$ or HRV-C, and the median and the interquartile range are depicted. 


\section{Colored ranges}

HRV-A

HRV-C

HRV-B

HRV-unclassified

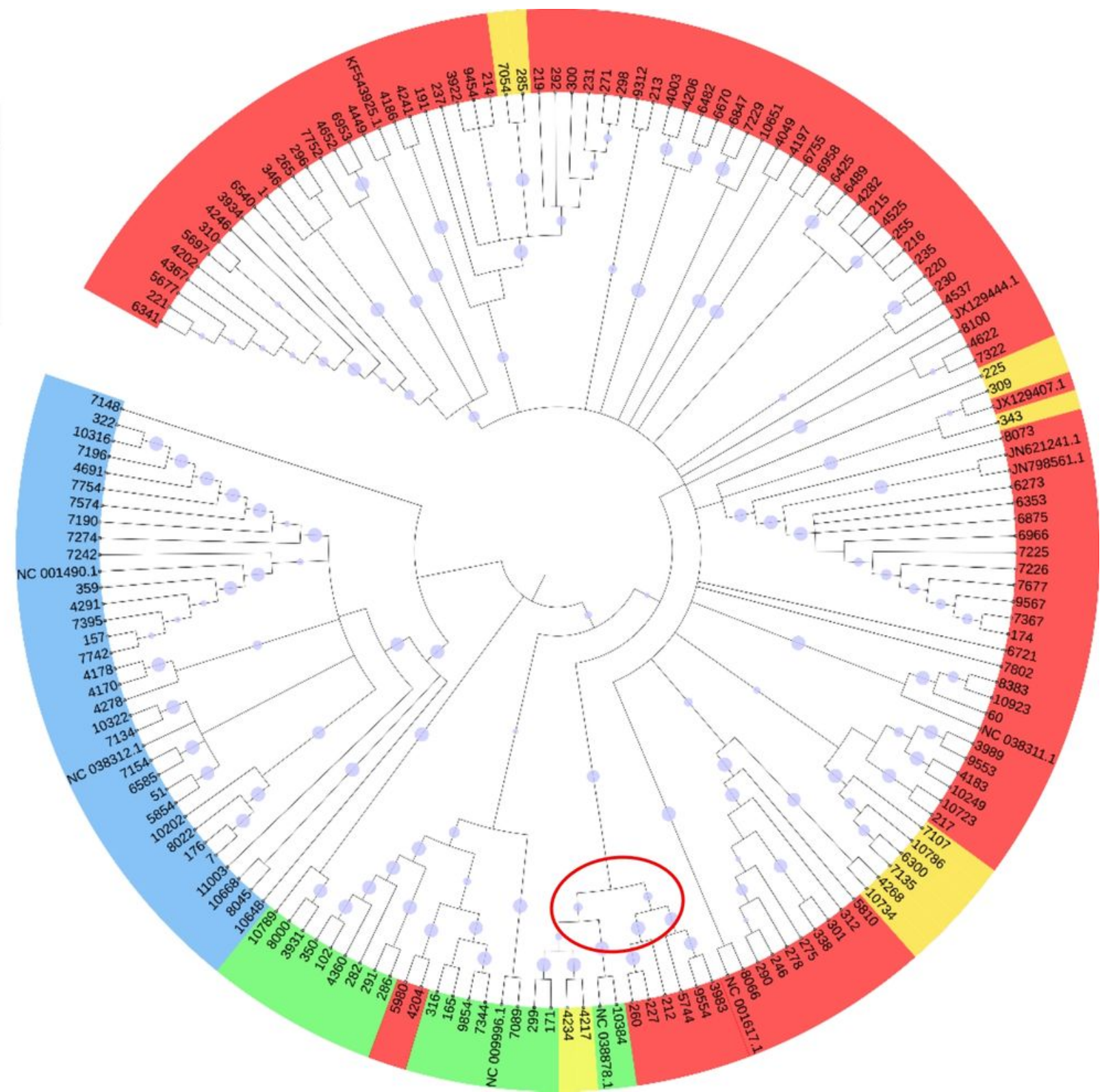

bootstrap

0.6

0.7

0.8

0.9

( ) 1

Figure 4

Phylogenetic analysis of the HRV 5'UTR using the Neighbor-Joining method. Multiple sequence alignment and an unrooted phylogenic tree were generated with neighbor-joining method and bootstrap test (500 replications) using MEGA-X program and ClustalW. This analysis involved 170 nucleotide sequences including 160 samples sequences and 10 reference sequences. Reference sequences were represented by sequence ID of GenBank, and specimens by clinical sample numbers. All positions with less than $60 \%$ site coverage were eliminated. The red circles are the different genotypic sequences located under the same branch. 

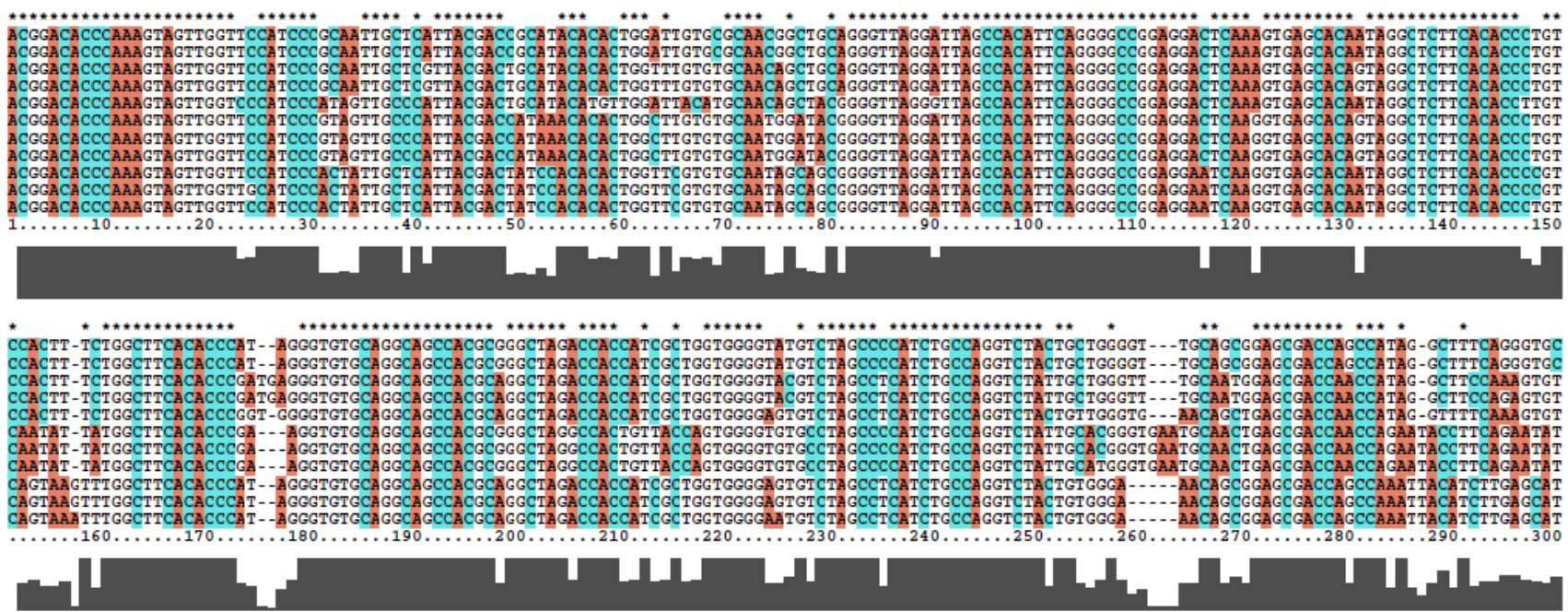

** $* * * * * * * * * * * * * * * * * * * * * * * * * * * * *$

*****************

4217
4234
299
171
10384
260
227
212
9554
3983
5744

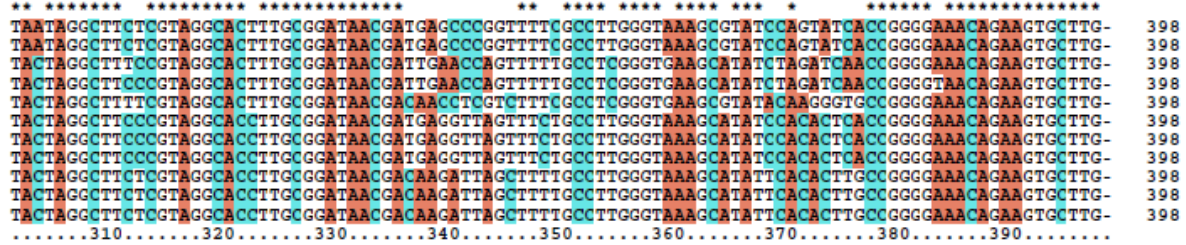

.

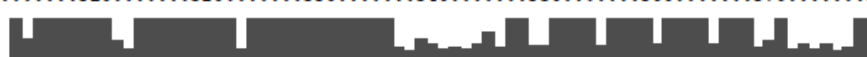

\section{Figure 5}

Multiple sequence comparison. The 11 sequences that were present in the same branch were aligned by Clustalw in MEGA X and exported visualization files with Clustalx software. The asterisk on the sequence indicates conserved regions. 


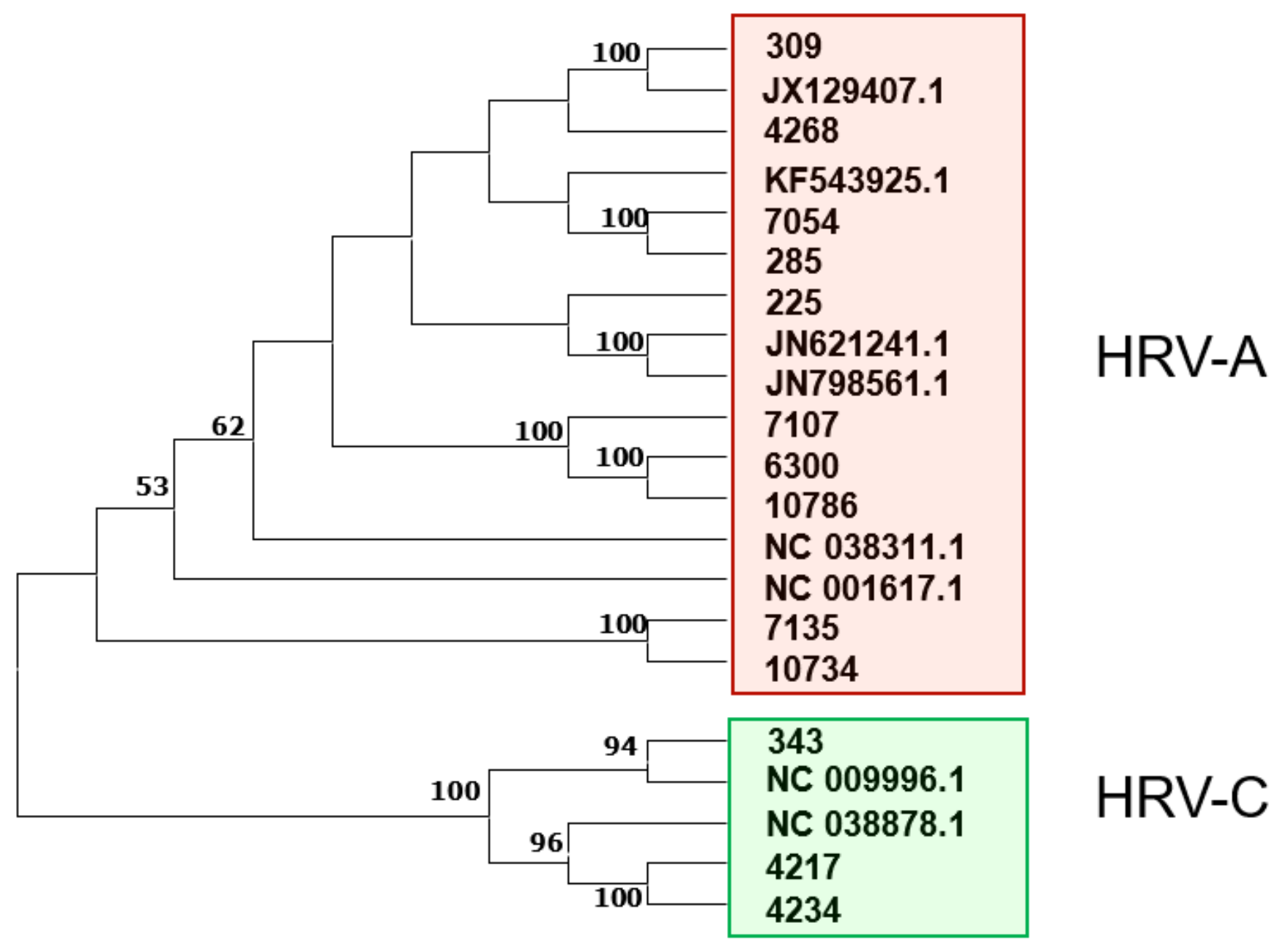

Figure 6

Phylogenetic analysis of the unclassified samples of VP4/VP2 using the Neighbor-Joining method. 13 sequences alignment and an unrooted phylogenic tree were generated with neighbor-joining method and bootstrap test (500 replications) using MEGA-X program and ClustalW. This analysis involved 21 nucleotide sequences including 13 samples sequences and 8 reference sequences. Reference sequences were represented by sequence ID of GenBank, and specimens by clinical sample numbers. All positions with less than $50 \%$ site coverage were eliminated. 